\title{
Impact of Socioeconomic Status, Ethnicity, and Urbanization on Risk Factor Profiles of Cardiovascular Disease in Africa
}

\author{
Karen Sliwa, MD, PhD, FESC, FACC; Letitia Acquah, MD, MSc; \\ Bernard J. Gersh, MB, ChB, DPhil, MACC, FRCP; Ana Olga Mocumbi, MD, PhD, FESC
}

\begin{abstract}
Africa is a continent characterized by marked ethnic, sociodemographic, and economic diversity, with profound changes in many regions over the past 2 decades. This diversity has an impact on cardiovascular disease presentation and outcomes. Within Africa and within the individual countries, one can find regions having predominantly communicable diseases such as rheumatic heart disease, tuberculous pericarditis, or cardiomyopathy and others having a marked increase in noncommunicable disease such as hypertension and hypertensive heart disease. Ischemic heart disease remains rare in most countries. Difficulties in the planning and implementation of effective health care in most African countries are compounded by a paucity of studies and a low rate of investment in research and data acquisition. The fiduciary responsibilities of companies working in Africa should include the effective and efficient use of natural resources to promote the overall health of populations. (Circulation. 2016;133:1199-1208. DOI: 10.1161/ CIRCULATIONAHA.114.008730.)
\end{abstract}

Key Words: cardiovascular diseases $\boldsymbol{\square}$ epidemiology

$\mathrm{C}$ ardiovascular diseases (CVDs) with infectious and nutritional origins have long been the principal forms of heart disease in Africa. In this article, we use the term CVD resulting from communicable causes for rheumatic heart disease, HIV, virus-induced cardiomyopathy, etc. For CVD resulting from noncommunicable causes, for example, hypertension, cardiomyopathy, and myocardial infarction, we use the term CVD resulting from noncommunicable causes.

The epidemiological transition with a subsequent increase in hypertension and diabetes mellitus has seen an increased prevalence of noncommunicable forms of heart disease in most African populations. ${ }^{1}$ This phenomenon is driven largely by population-wide changes in demographic, social, and economic status, with associated changes in lifestyle habits..$^{2-4}$ Nonetheless, the incidence of communicable CVD is sustained and fueled by the epidemics of the HIV/AIDS, rheumatic heart disease, tuberculosis, and parasitic infections with cardiac involvement. ${ }^{5-7}$ In parallel, the rapid and marked increase in the prevalence of cardiovascular risk factors raises the spectrum of a potential epidemic of noncommunicable CVDs in an environment characterized by limited resources and infrastructure to combat these threats.

The aim of this thematic review is to describe the current knowledge of the impact of socioeconomic status and its relationship with risk factor profiles on CVD and regional epidemiology within Africa. Furthermore, we aim to review current and novel strategies for disease prevention, treatment, and behavioral change, as well as the progress of policy development. This is within the context of the substantial gaps in available data and its profound limitations. For many countries, we have either no data or only data collected within certain urban areas and certain population groups. In this article, we have summarized the gaps in knowledge and resources and our recommendations for the way forward, which we hope will assist in future healthcare planning.

\section{Statistical Capacities for Gross Domestic Product Assessment in African Economies and Its Impact on Disease}

The economic classification of countries has traditionally been based on the gross domestic product (GDP). The International Monetary Fund recommends that the base year for GDP estimation should be updated every 5 years. However, as Jerven ${ }^{8,9}$ highlighted in his recent perspective article and book, only a few countries in Africa are able to fulfill that standard; for most countries, the base years are about a decade or older. These significant errors are highlighted by recent examples of Ghana and Nigeria. Ghana's GDP was recalculated on the basis of a change in statistical methodology, and the country's GDP was revised upward to such an extent that Ghana's recorded GDP per capita almost doubled, leading to a reclassification from a low-income

\footnotetext{
From Hatter Institute for Cardiovascular Research in Africa \& IDM, Department of Medicine, Faculty of Health Sciences, University of Cape Town, South Africa (K.S.); Soweto Cardiovascular Research Unit, University of the Witwatersrand, Johannesburg, South Africa (K.S.); Medical Research Council of South Africa, Inter-Cape Heart Group, Cape Town, South Africa (K.S.); Division of Hospital Internal Medicine, Department of Medicine, Mayo Clinic Hospitals, Rochester, MN (L.A.); Division of Cardiovascular Diseases, Mayo Clinic College of Medicine, Mayo Clinic, Rochester, MN (B.J.G.); Instituto Nacional de Saúde, Maputo, Mozambique (A.O.M.); and Universidade Eduardo Mondlane, Maputo, Mozambique (A.O.M.).

Correspondence to Karen Sliwa, MD, PhD, FESC, FACC, Hatter Institute for Cardiovascular Research in Africa, Department of Medicine, Groote Schuur Hospital, 3 Anzio Rd, University of Cape Town, Cape Town 7935, South Africa. E-mail Karen.Sliwa-Hahnle@uct.ac.za

(C) 2016 American Heart Association, Inc.
} 


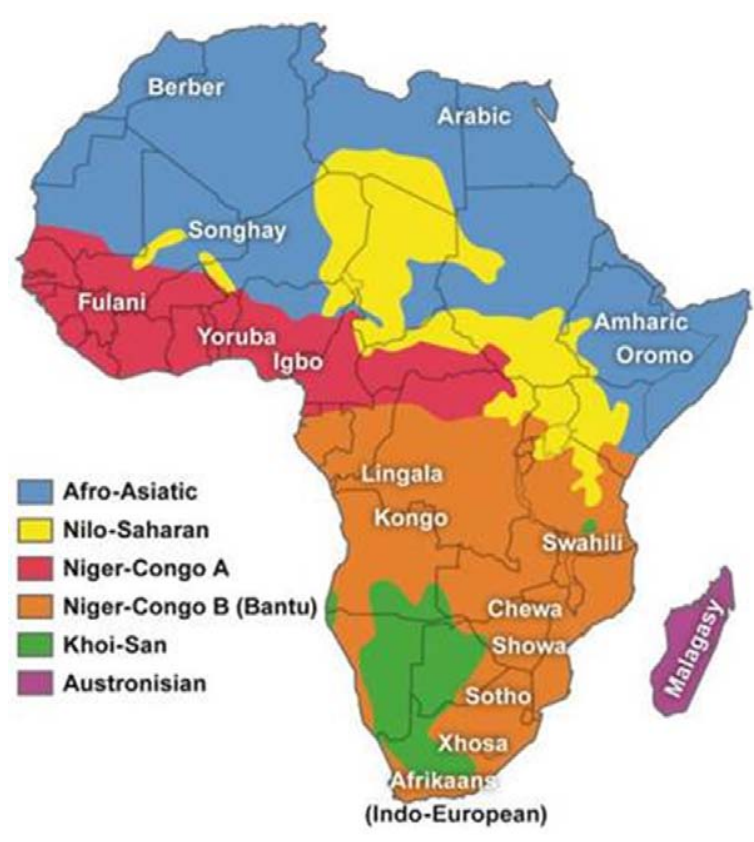

Figure 1. African language families and some major African languages. Color-coded regions of the African continent representing examples of major languages derived from major language phyla of African language families. Adapted from image created by Mark Dingemanse, according to classification by Joseph $\mathrm{H}$. Greenberg, and released under the Creative Commons Attribution 2.5 license.

country to a lower-middle-income country. This dramatic jump was based on changing the base year from 1993 to $2006 .{ }^{8}$ For Nigeria, the most populous nation on the African continent, the base year is 1990 , and a revision is underway. Nigeria's economy is $\approx 50$ times the size of that of an African country with one of the lowest economies, for example, Malawi. Doubling the estimates of the size of Nigeria's economy would have an enormous impact on any economic assessment of the continent. The poor quality of the current data makes any factual statement of the current aggregate trends of growth and poverty and subsequent continentwide estimates uncertain, thus complicating the prediction of healthcare consequences for individual African countries. GDP numbers and other statistics such as health statistics, which we often treat as fact, bear with them the caveat that these are often simply numbers or estimations produced under the most difficult circumstances. In particular, we have a paucity of knowledge of those who are the poorest or live in the most remote regions in Africa, as is the case among many indigenous populations. To change that situation, we would need recognition of the importance of data collection, substantial funding, and human resources. For most African countries, a typical Living Standard Measurement Survey, as developed by the Development Research Group of the World Bank, to improve the type and quality of household data collection by statistical offices in developing countries would be desirable. An e-learning course is available on their Web site (www.econ.worldbank.org). At present, most African countries do not have a specific budgetary allocation for that purpose because of either a lack of resources or a lack of a perceived need for such surveys.

\section{Africa: A Continent Characterized by a Marked Ethnic, Sociodemographic, and Economic Diversity: Impact on CVD Presentation and Outcomes}

Beside health surveys, a broad range of parameters are needed to assess the impact of economic development on cardiovascular and other manifestations of disease on different African populations. The African continent is highly diverse ethnically. This is reflected in Figure 1, which exhibits color-coded regions of the African continent representing the 4 phyla of African language families consisting of an estimated 2000 languages. ${ }^{10}$ Mother language defines ethnic groups and, to some extent, behavior based on traditions. Current political borders arise to a large extent from the colonial era and thus are not necessarily representative of the specific African ethnicities.

Africa has a large number of countries in the highest income inequality tertiles (Table 1 ). ${ }^{11}$ The Gini index or Gini

Table 1. Analysis of 78 Countries Stratified by Income Inequality.

\begin{tabular}{|c|c|c|}
\hline Low Gini $(<0.38)$ & Medium Gini (0.38-0.55) & High Gini (>0.55) \\
\hline Australia & Argentina & Bolivia \\
\hline Austria & Bangladesh & Brazil \\
\hline Belgium & Botswana* & Burkina Faso* \\
\hline Canada & Bulgaria & Cameroon* \\
\hline China & Chile & Central African Republic* \\
\hline Denmark & Costa Rica & Colombia \\
\hline Finland & Dominica & Ecuador \\
\hline France & Egypt* $^{*}$ & Gambia* \\
\hline Great Britain & El Salvador & Guinea \\
\hline Greece & Ethiopia* & Honduras \\
\hline Ireland & Ghana* & Jamaica \\
\hline Italy & Guatemala & Lesotho* \\
\hline Japan & Guyana & Madagascar* \\
\hline Luxembourg & Indonesia & Mali* \\
\hline Mongolia & Jordan & Mauritania* \\
\hline Netherlands & Malaysia & Mexico \\
\hline New Zealand & Nepal & Nicaragua \\
\hline Norway & Nigeria* & Panama \\
\hline Portugal & Peru & Paraguay \\
\hline Republic of Korea & Philippines & Senegal* \\
\hline Romania & Sri Lanka & South Africa* \\
\hline Spain & Trinidad and Tobago & Swaziland* \\
\hline Sweden & Turkey & Thailand \\
\hline Switzerland & Uganda* & $\begin{array}{c}\text { United Republic of } \\
\text { Tanzania* }^{*}\end{array}$ \\
\hline United States & Uruguay & Zambia* \\
\hline Vietnam & Venezuela & Zimbabwe* \\
\hline
\end{tabular}

Data were taken from Kim et al. ${ }^{11}$

${ }^{*}$ African countries. 
coefficient is a measure of statistical dispersion and is used to represent the extent to which the distribution of consumption expenditure or income per person (or household) within a specific society differs from a perfectly equal distribution and is the most commonly used measure of inequality. The Lorenz curve is a graphical representation of wealth or income distribution and is used to map the collective percentages of total income received against the number of recipients, beginning with the individual or household with the lowest income. The area between the Lorenz curve and a hypothetical line of absolute equality is expressed as a percentage of the maximum area under the line, as defined by the Gini index. A Gini index of 0 indicates perfect equality, and an index of 100 implies perfect inequality (http://data.worldbank.org/indicator/SI.POV.GINI?page=5). A wide variety of Gini indexes for African countries means that within many African countries certain population groups are wealthy and experience a very different lifestyle, which includes access to health care, compared with other population groups living in absolute poverty. The implications of such differences are reflected in the profile of diseases encountered within the continent as a whole: A double burden in which communicable and noncommunicable diseases linked to poverty coexist with risk factors linked to obesity, urbanization, industrialization, and others. ${ }^{12}$

This heterogeneity in different ethnic groups within a country is highlighted in the INTERHEART Africa study, ${ }^{13,14}$ reporting on the impact of education and income on risk factors for acute myocardial infarction among different ethnic groups living in South Africa.
A standardized case-control study of myocardial infarction, from which a total of 578 cases and 789 controls were recruited in the African continent (52 countries), was the basis of the INTERHEART Africa Study. In the black population, those who had $<8$ years of schooling as opposed to those with higher education showed an increased risk of acute myocardial infarction (odds ratio, 1.86; 95\% confidence interval, 1.06$3.25)$. In contrast, there was no difference observed in the colored African group (odds ratio, 0.71;95\% confidence interval, 0.30-1.68). The direction of association was just the opposite for the European/other African groups. In these groups, those with tertiary education had a significantly lower risk (odds ratio, 0.30; 95\% confidence interval, 0.15-0.58) compared with those who attended school for $<8$ years. Probability values for the interaction of education and ethnicity and for the income-ethnicity interaction are $<0.0001$ (Figure 2).

The country-level risk factor estimates for 199 countries from a systematic analysis of population-based data by Danaei and colleagues ${ }^{4}$ were used to analyze the trend in associations between per capita GDP and cardiovascular risk factors. A worldwide network of clinical and public health researchers and practitioners, the Global Burden of Metabolic Risk Factors of Chronic Diseases Collaborating Group, has identified a unique data set on 5 risk factors: body mass index (BMI), blood pressure, serum cholesterol, fasting plasma glucose, and diabetes mellitus.

In 1980, 3 major metabolic risk factors for CVD, namely systolic blood pressure (SBP), total cholesterol, and BMI, were positively associated with income per country and Western diet at the national level. Re-evaluation of these factors in
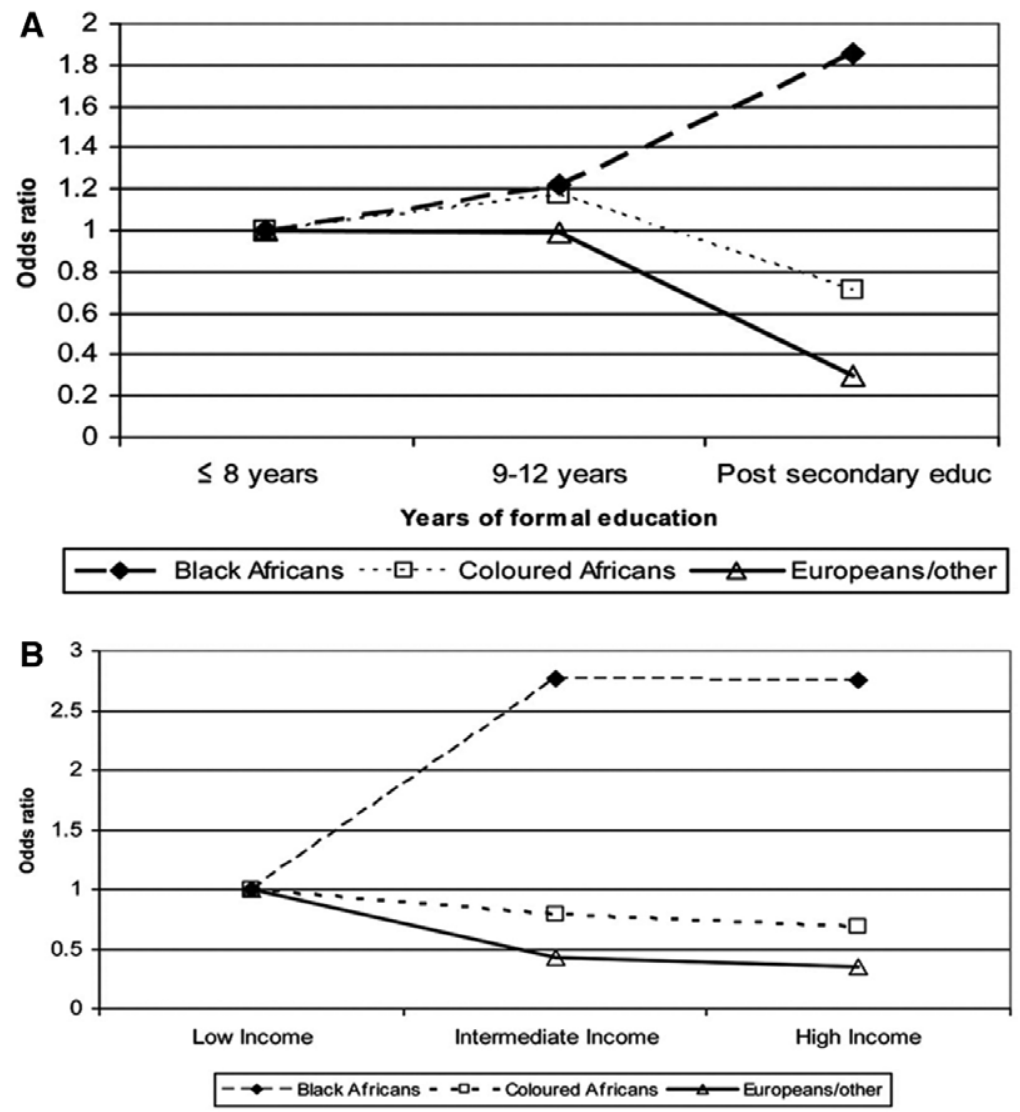

Figure 2. Impact of education and income on risk factors for acute myocardial infarction in different ethnic groups living in South Africa. Odds ratio (OR) associated with increasing formal education by ethnic group (A) and with increasing income by ethnic group (B). Adapted from Steyn et al. ${ }^{14}$ 
2008 demonstrated that only serum cholesterol levels retained a strong positive association with national income.

Data from the World Health Statistics for the African continent are subject to considerable uncertainty. They provide estimates that are based on data from multiple source, with limited availability and quality as a result of the inherent weaknesses in the statistical and health information systems in many African countries. The 2012 World Health Statistics referring to Africa report the following:

- The median prevalence of raised fasting blood glucose (ie, fasting glucose $\geq 126 \mathrm{mg} / \mathrm{dL}$ [7.0 mmol/L] or taking medication for raised blood glucose) among adults $\geq 25$ years of age was $9.9 \%$ for men and $9.5 \%$ for women.

- The median prevalence of raised blood pressure (ie, SBP $\geq 140 \mathrm{~mm} \mathrm{Hg}$ or diastolic blood pressure $\geq 90 \mathrm{~mm} \mathrm{Hg}$ ) among adults $\geq 25$ years of age was $34.6 \%$ for men and $28.3 \%$ for women.

- The median prevalence of obesity (ie, BMI $\geq 30 \mathrm{~kg} / \mathrm{m}^{2}$ ) among adults $\geq 20$ years of age was $14.9 \%$ for men and $22.1 \%$ for women.

These reported figures are age-standardized point estimates that are adjusted for uncertainty ranges (available on the Global Health Observatory Web site, http://www.who.int/ gho).

In regard to the estimated prevalence of diabetes mellitus, there was relatively little variation across income groups and in different countries. This ranged from $8 \%$ in both sexes in low-income countries to $10 \%$ in high-middle-income countries. (http://www.who.int/nmh/publications/ncd_report2010)

The authors concluded that the changing associations between metabolic risk factors and macroeconomic variables suggested an upcoming global pandemic of hyperglycemia and diabetes mellitus, together with high blood pressure, in low-income countries regardless of income. ${ }^{4}$

\section{Africa Cross-Country Associations of CVDs and Risk Factors Interlinked With GDP and Income Inequality}

A recent series of publications in The Lancet ${ }^{15-18}$ reported national, regional, and global trends in the prevalence of BMI, serum cholesterol, plasma glucose, and SBP since 1980 in 199 countries and territories, including data from $>5$ million participants.

Obesity prevalence in men and women varied fundamentally within Africa (Figure 3A), with the prevalence of overweight and obese women being highest in southern Africa in 2008 and still remarkably low in West, East, and Central Africa. The prevalence rate of obesity in African men is in general lower than that in women. ${ }^{15}$ Serum total cholesterol in 2008 was lowest in Sub-Saharan Africa at $4.08 \mathrm{mmol} / \mathrm{L}(3.82-$ $4.34 \mathrm{mmol} / \mathrm{L}$ ) for men, and $4.27 \mathrm{mmol} / \mathrm{L}(3.99-4.56 \mathrm{mmol} / \mathrm{L})$ for women and highest in Cameroon, Namibia, Botswana, and Tanzania, according to the World Health Organization (WHO) Infobase in 2010. ${ }^{16}$ Mean fasting plasma glucose in 2008 was also lowest in Sub-Saharan Africa. However, investigating the change in country age-standardized SBP between 1980 and 2008 demonstrated a rise in SBP in East Africa for both sexes and in West Africa for women, with the increase ranging from 0.8 to $1.6 \mathrm{~mm} \mathrm{Hg}$ per decade in men and 1.0 to $2.7 \mathrm{~mm} \mathrm{Hg}$ per decade in women. According to the WHO country-specific data on the mean prevalence rates of hypertension among adult men and women, the mean prevalence rates of hypertension in West (ie, $43 \%$ versus $40 \%$ ) and East (ie, $40 \%$ versus $37 \%$ ) African men are higher than those in women, whereas those in southern African males (ie, 34\% versus 40\%) are lower than in females. The mean prevalence rates of hypertension are equal among adult northern African men and women (ie, $39 \%$ versus $38 \%$ ).

However, the authors of the articles by the Global Burden of Metabolic Risk Factors of Chronic Diseases Collaborating Group clearly highlight that the main limitation of their studies is that despite extensive attempts at data collection, many countries do not have specific data, especially for the 1980s. ${ }^{15}$ The absence of those data is reflected in wider uncertainty intervals. In total, SBP is currently highest in low- and middle-income countries worldwide, including many African countries.

Studies have identified economic development, as measured by the GDP per capita, as a predictor of CVD risk factors. In a cross-national analysis of 85 countries, Ezzati et $\mathrm{al}^{23}$ observed a concave and nonlinear association between GDP per capita, mean BMI, and serum cholesterol, with higher risk factor levels at intermediate (versus low) GDP levels and comparable to slightly lower risk factor levels at high (versus intermediate) GDP levels. Data were not specifically analyzed per region, for example, Africa.

Kim et al $^{11}$ reported cross-country associations of income inequality with CVD and risk factors. They collected a large set of data from 78 countries, within which 14 of the 26 countries in the highest inequality tertile defined by the Gini coefficient were located on the African continent (Table 1). ${ }^{11}$ Income inequality is likely to have an effect on cardiovascular risk factors, the epidemiological transition within the different African countries, and the many ethnic groups living in rural and urban areas.

Pampel et $\mathrm{al}^{24}$ and Goyal et $\mathrm{al}^{25}$ described that although socioeconomic status and weight have a positive association in low-income countries, they have a negative association in higher-income countries. However, the authors introduce a caveat emphasizing that the relationship and its causes need to be tested in large and diverse national databases.

Figure 3A through 3D shows the prevalence of cardiovascular risk factors such as obesity, hypertension, cholesterol, cigarette/tobacco smoking, and diabetes mellitus within the different regions of Africa as published from the WHO InfoBase, International Federation of Diabetes, and World Bank. It is challenging to find data on the minimum legal ages of smoking and, more important, the implementation and compliance with specific laws and regulations to address the worsening epidemic of tobacco and tobacco-associated illnesses in various African countries. Many African countries have not complied fully with the Framework Convention on Tobacco Control. The Framework Convention on Tobacco Control legislates protection from tobacco smoke exposure; the packaging and labeling of tobacco products; and the advertising, promotion, and sponsorship of tobacco products. 
A Prevalence Rates of Adult Obesity (Body Mass Index $\geq 30$ ) in Africa, 2005

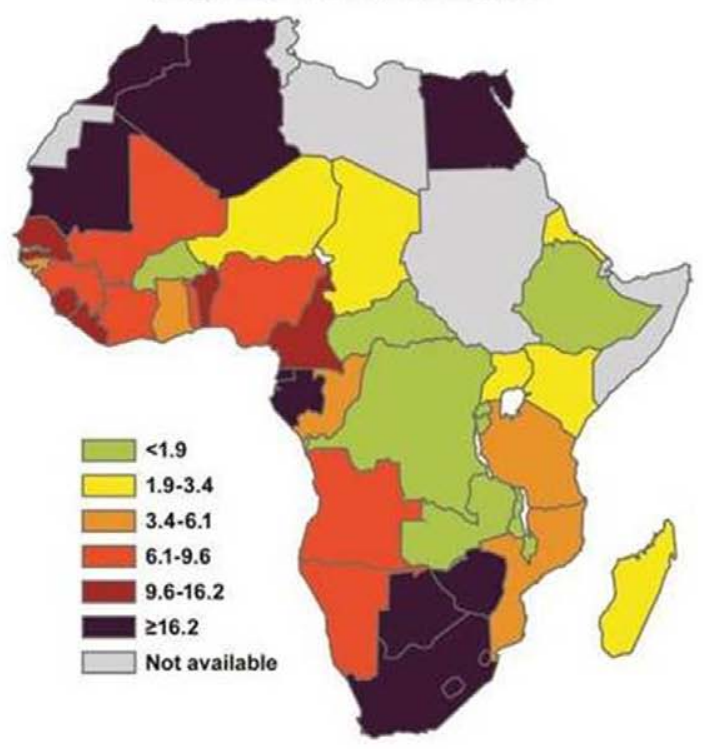

C

Estimated Mean Cholesterol (mmol// Total Cholesterol) Males and Females $\geq 15$ yo, 2010

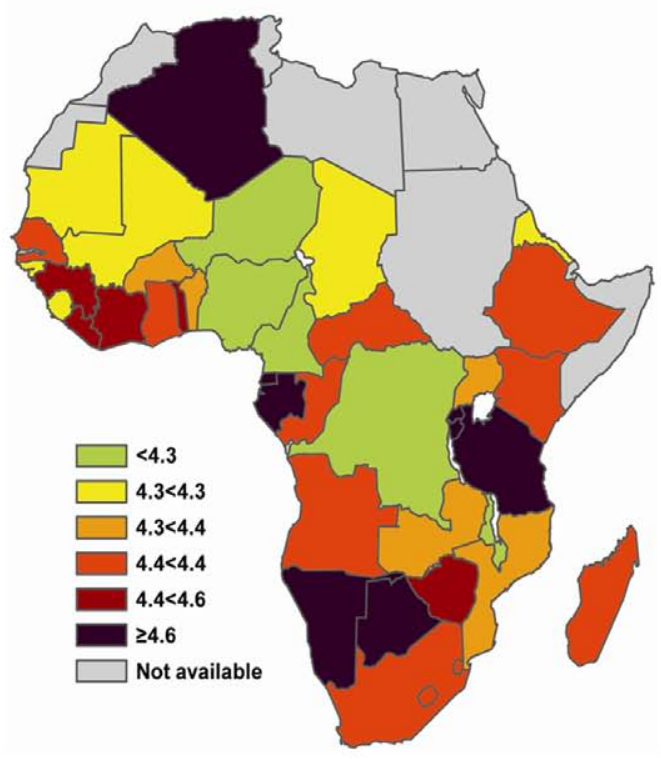

B

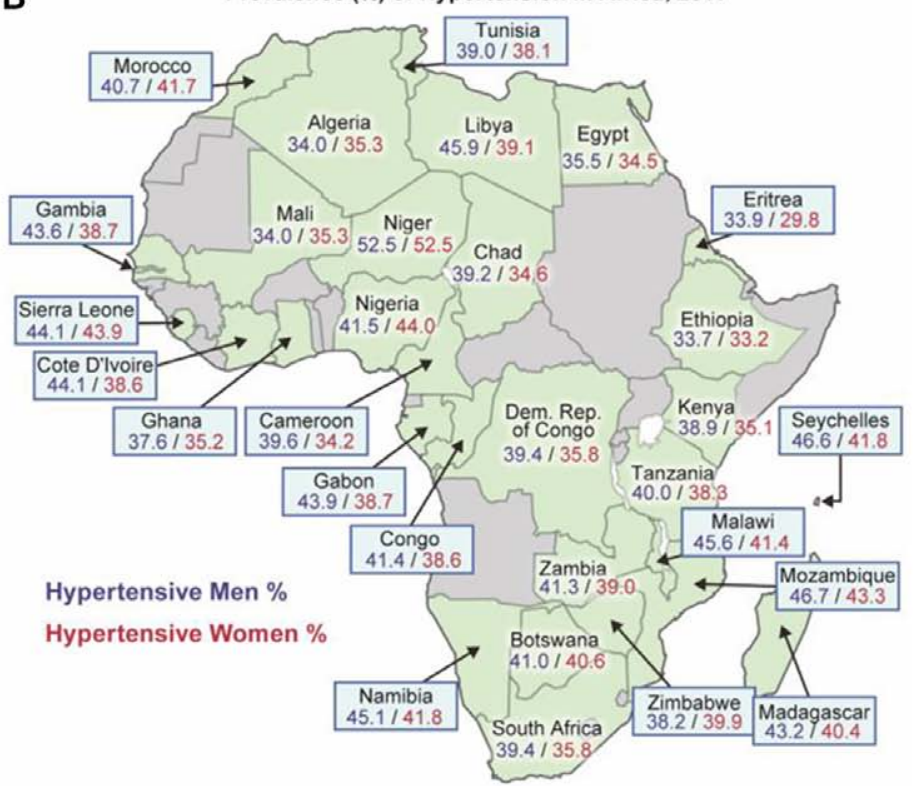

D

Age-Standarized Prevalence Estimates for Smoking Cigarettes: Current users - Males and Females Aged $\geq 15$ years in 2006

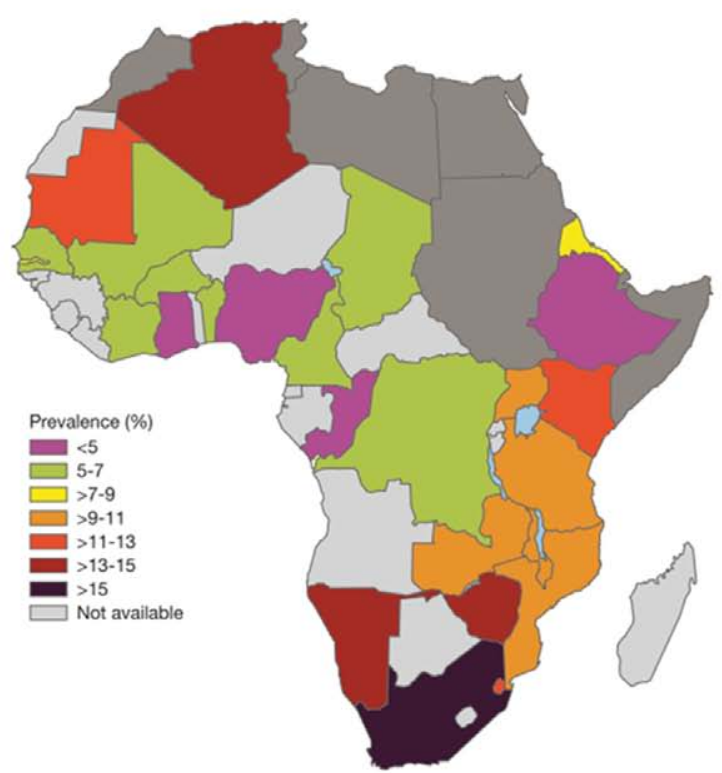

Figure 3. A, Prevalence rates of adult obesity (body mass index $\left[\mathrm{kg} / \mathrm{m}^{2}\right]$ ) in Africa (2005), as reported by the World Health Organization InfoBase, International Federation of Diabetes, and World Bank (percent of adults $\geq 15$ years of age). Combined estimates of mean prevalence rates of adult obesity in males and females are color-coded in the legend. Adapted from Diabetes Federation ${ }^{19}$ with permission. B, Prevalence rates of hypertension among adults $\geq 15$ years of age in Africa (2011), as reported by the World Health Organization (WHO) InfoBase, International Federation of Diabetes, and World Bank. Mean prevalence rates of hypertensive males versus females are indicated in blue and red, respectively. Adapted from the Non-Communicable Disease Country-Specific Profiles 2011: WHO Global Report. ${ }^{20} \mathbf{C}$, Prevalence rates of estimated mean cholesterol (mmol/L total cholesterol) in Africa (2010), as reported by the WHO InfoBase, International Federation of Diabetes, and World Bank. Combined estimated mean cholesterol prevalence rates (\%) for males and females indicated by color code in the legend. Adapted from the WHO Global Comparable Estimates. ${ }^{21} \mathbf{D}$, Combined estimated prevalence rates (percent) for age- and sex-standardized cigarette smoking, as reported by the World Health Organization (WHO) InfoBase, International Federation of Diabetes, and World Bank. Combined age-standardized prevalence estimates of males and females who are currently smoking cigarettes are color-coded in the legend. Adapted from the WHO Report on the Global Tobacco Epidemic 2009: Implementing Smoke-Free Environments. ${ }^{22}$

In 2011, Tumwine, ${ }^{26}$ of the Health and Environmental Rights Organization, advocated the prioritization of resources for capacity building in African countries. The aim was to facilitate the drafting of a strong Framework Convention on
Tobacco Control-compliant legislation that includes research on tobacco use in Africa with the objective of informing policy making and boosting the political will of African countries. These measures are aimed at successfully counteracting the 
strong influence of the tobacco industry in recruiting smokers in African countries.

Pampel $^{27}$ examined data on tobacco use among men (age, 15-54 years) and women (age, 15-49 years) from 16 demographic health surveys in 14 Sub-Saharan countries. According to Pampel's analysis, the gradation of the prevalence of cigarette smoking increases from among West-Central African men (lowest use) to southern African men (medium use) and then to men from Madagascar and East-Central Africa (highest use). The highest prevalence of cigarette smoking was observed among urban, less educated men and women of lower socioeconomic status, although the prevalence rates of women cigarette smokers were lower than the rates for their male counterparts.

The observed region-specific risk factors are quite complex to explain, and associations between region-specific variables and the prevalence rates of the cardiovascular risk factors may not have been definitively measured as a result of financial and infrastructural difficulties in designing studies to capture such data. However, in general, southern Africa (particularly South Africa), and northwest Africa, for example, Algeria, have the highest percentages of obesity, undiagnosed diabetes mellitus, smoking, and high cholesterol. SBP levels are generally high but particularly high in western and eastern Africa. However, some of the findings are puzzling, for example, the fact that the estimated mean cholesterol for the populations of Namibia and Botswana is $>4.6 \mathrm{mmol} / \mathrm{L}$ (Figure $3 \mathrm{C}$ ) and among the highest on the continent. Both countries have a particularly high proportion of people still living a rural lifestyle, for example, the Himba and Ovambo in northern Namibia and the Khoi-San in northern South Africa, Botswana, and Namibia. Many are herders and migrants. It is very unlikely that people belonging to these ethnic groups have high cholesterol. The findings used in this WHO global comparable estimate are probably based on findings from urban populations and small studies.

Mensah $^{3}$ provided a descriptive epidemiology of cardiovascular risk factors and diabetes mellitus in Sub-Saharan Africa. Rising BMI, particularly in women from southern Africa, and high blood pressure in East Africa for both sexes and in West Africa for women were the most important cardiovascular risk factors.

\section{Research and Development in Africa and Impact on CVD Research and Management}

There is a link between investment in research and macroeconomic growth in that the fraction of GDP that countries spend on research and development (R\&D) is highly correlated with the fraction of their population who are scientists and engineers. ${ }^{28}$ Technology, although not exactly a form of capital, is related to human and intellectual capital and is capable of generating positive feedback, which enables a virtuous cycle of exponential growth. ${ }^{29}$ To the classic factors of production that affect exponential economic growth, we might add various forms of human capital such as investment in education and intellectual property. ${ }^{28}$

It would appear that nations who spend close to $3 \%$ of their GDP on R\&D are usually more successful when competing for economic growth opportunities than those who spend less. ${ }^{28}$ By world standards, despite having risen in most
African countries between 2002 and 2008, the GDP per capita remains low. ${ }^{30}$ Although Africa's contribution to global R\&D efforts have progressed, a number of challenges, including budgetary/financial constraints, need to be addressed (http:// www.unesco.org/new/en/media-services/singleview/news/ research_and_development_africa_is_making_progress_ despite_major_challenges/\#.VUzXis5LNfQ).

Only about $0.3 \%$ of GDP of the continent is devoted to $\mathrm{R} \& \mathrm{D}$, which is 7 times less than that spent by industrialized countries on this sector. Although recent economic data show that Nigeria's economy has overtaken South Africa's to become the continent's largest and the world's 26th most productive, South Africa spends more on R\&D. With its investment rising from $0.73 \%$ in 2001 to $0.97 \%$ in 2007 as a proportion of GDP, South Africa is the only country in the continent that comes close to the $1 \%$ mark for the R\&D expenditure and leads in terms of scientific publications, with $46 \%$ of the continent's entire share, far ahead of Nigeria $(11.4 \%){ }^{30}$

Major challenge for R\&D in Africa are the low literacy rate, poor quality of education, and brain drain. At least one third of all African researchers or those with engineering degrees were living and working in developed countries in 2009. Several African countries (eg, Uganda, Cameroon, Botswana) are striving to address this problem by increasing academic' salaries, as well as offering other incentives. ${ }^{30}$ Nonetheless, to reach the suggested target of 1000 researchers per 1 million population by 2025, radical changes will need to be implemented..$^{30} \mathrm{~A}$ fundamental issue, which will take time, vision, and a fundamental commitment from governments to be overcome, is the overall lack of resources and competing demands for the treatment and prevention of both communicable and noncommunicable diseases. It is imperative that the R\&D objectives be specifically focused and tailored toward those disease entities that are highly prevalent on the African continent and on issues and obstacles in regard to documenting their epidemiology, treatment, and prevention.

The poor state of R\&D in Africa, which explains in part the lack of population-wide data, has important implications for research on CVD prevalence, risk factors, and outcomes. The shortage of trained physicians and cardiologists, inadequate specialized cardiac facilities and equipment, and low levels of education, as well as lack of patient and public awareness, may lead to among patients lead many patients not having access to basic diagnostic facilities such as electrocardiography and echocardiography, medical therapies (eg, streptokinase, $\beta$-blockers), and advanced cardiac care. In addition, many regions have no access to any form of device treatment (eg, pacemaker insertion). The management of the communicable forms of CVD such as rheumatic heart disease, tuberculous pericarditis, and endomyocardial fibrosis (still the most common forms of CVD in many African countries) remains suboptimal because of a lack of screening facilities such as echocardiography and access to cardiothoracic surgery. ${ }^{31}$ Standard guidelines, for example, for acute and chronic heart failure, are subsequently not implemented, leading to poor patient outcome. Recently, the Pan-African Cardiac Society has been taking a more active role in context-appropriate guideline development and implementation. ${ }^{32}$ This society has representation from southern, eastern, western, 
and northern Africa and formed recently dedicated working groups to address the large burden of hypertension and heart failure on the continent.

\section{Implications for Clinical and Public Health Action}

In an article published in The Lancet under the theme of Global Governance for Health, Ottersen and colleagues ${ }^{33}$ highlighted that the unacceptable health inequities within and between countries globally and in Africa cannot be addressed within the health sector alone but require global political solutions. Improved global health in return increases trade, stability, and prosperity, and it would be in the self-interest of the higher-income countries to facilitate this process, in addition to the moral imperative. ${ }^{34}$ From a local and regional standpoint, however, it must be appreciated that the control of many of the risk factors will require social and economic engineering, as well as the involvement and will of the legislative branch. Such multidimensional approaches are essential to tackle the important factors such as second hand smoking, air pollution, provision of space, and facilities for exercise and school sporting activities. The Republic of the Seychelles, a rapidly developing small island state located east to Kenya, is a good example that this can be achieved by targeted action. Between 1989 and 2010, age-standardized stroke and myocardial infarction mortality decreased markedly which has been attributed to improved control of persons with high blood pressure and diabetes mellitus over time as well as increasing leisure time physical activity. ${ }^{35}$ This is remarkable because costly invasive procedures such as percutaneous coronary intervention and fibrinolysis are used only rarely in the Seychelles. Hence, the lessons to be learned from the Seychelles are that collection of goodquality data on cause-specific mortality and implementation of good clinical practice such as blood pressure control can lead to a reduction in morbidity and mortality. ${ }^{36}$

It would be of particular importance to get the cooperation of industry and food manufacturers to limit the advertising of unhealthy food choices, alcohol, and tobacco. In South Africa, a large food store has introduced a discount for low-glycemicindex breads, fruit, and vegetables, thus incentivizing healthy food choices. Several medical aid providers offer a discount on monthly fees if weight loss has been achieved, sports clubs are visited several times a week, and screening for CVD is followed by a certain age group. Figure $4^{37}$ summarizes the possible contributing factors to the epidemic of noncommunicable diseases that can be seen in many urban and rural parts of Africa and re-emphasizes that only a concerted effort from government, industry, and the health sector on both a global and a regional basis will stand a chance of telescoping the epidemiological transition and the epidemic of CVD in lowand middle-income countries, including the African continent.

Table 2 summarizes our recommendations based on the WHO "Best Buys" approach. It lists the gaps in knowledge and barriers to adequate management of noncommunicable diseases in a continent where health professionals' training and healthcare systems are designed to prevent and manage endemic communicable diseases such as malaria, tuberculosis, and HIV/AIDS. Because of the limited resources and lack of infrastructure for the diagnosis and management of noncommunicable diseases at the primary level, we suggest possible strategies toward strengthening health systems, focusing on 4 major areas: (1) the development of human resources, (2) an improvement in infrastructure for diagnosis and management of noncommunicable diseases at the primary level, (3) implementation of basic registries for mapping of noncommunicable diseases and risk factors in different populations and age groups, and (4) the establishment of partnerships with stakeholders outside the health sector.

Mapping of the pattern of noncommunicable diseases will be needed to allow health policy makers to increase access to diagnostic tools and low-cost generic primary prevention medications. Innovative strategies will be needed, building on current strategies on task shifting or task sharing in Rwanda ${ }^{38}$ and Mozambique, ${ }^{39,40}$ the results of which are encouraging.

Although thought to further exacerbate income and healthcare inequality, industry involvement in promoting high-tech imaging, devices, and procedures may be revolutionary. If cost-effective strategies are chosen, directed to the relevant problems and tailored to the local conditions, hightech tools may be developed both to assess the epidemiology and to improve the management of noncommunicable diseases in low-resource areas. ${ }^{38}$ In line with this, African

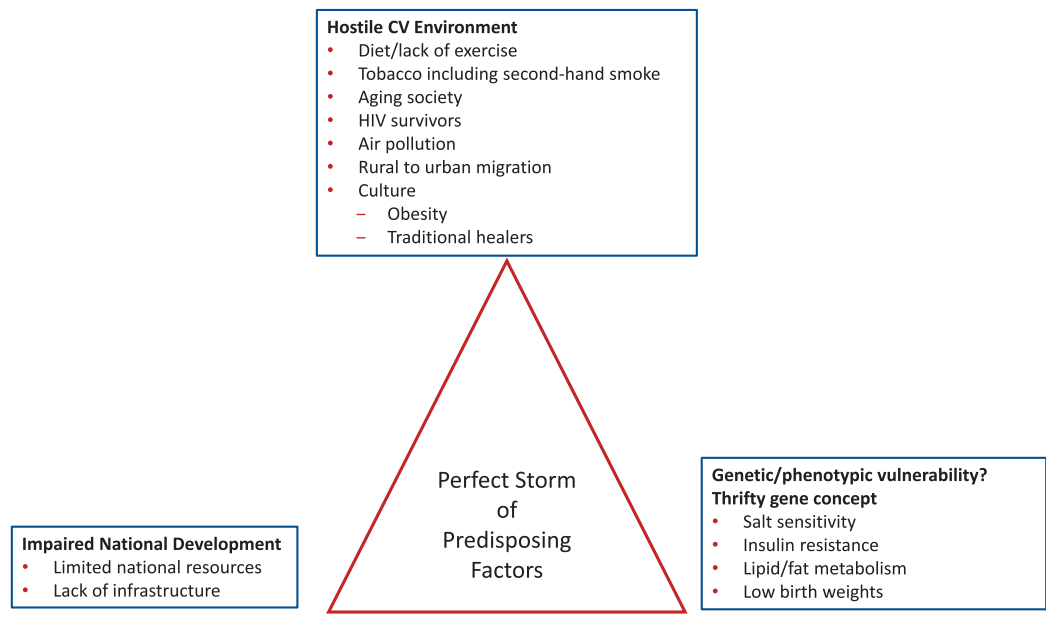

Figure 4. Factors contributing to the epidemic of cardiovascular disease in low- and middleincome countries. Adapted from Gersh et al. Novel therapeutic concepts: the epidemic of cardiovascular disease in the developing world: global implications. Eur Heart J. 2010;31:642$648 .^{37}$ Copyright (C) 2010, European Society of Cardiology. 
Table 2. Summary of our Recommendations Based on the WHO "Best Buys" and What Could Be the Way Forward

\begin{tabular}{|c|c|}
\hline Gaps in Knowledge and Resources & Suggested Next Steps \\
\hline $\begin{array}{l}\text { Reduced pool of trained health workers } \\
\text { Low rates of graduates from health } \\
\text { professional schools } \\
\text { Internal and External brain drain }\end{array}$ & $\begin{array}{l}\text { Use of nonphysician technicians and medical officers for service provision for most prevalent CVD } \\
\text { Train community health workers for primary prevention and early detection of risk factors in the communities } \\
\text { Involve community health workers in support for follow-up of cardiovascular conditions and improvement of } \\
\text { adherence to medication } \\
\text { Improve salaries for health professionals and academics, and promote career development and other incentives } \\
\text { for teaching roles }\end{array}$ \\
\hline $\begin{array}{l}\text { Health system weaknesses in CVD area } \\
\text { Clinician apathy and lack of continuous } \\
\text { training } \\
\text { Lack of routine collection of CVD data } \\
\text { Low and inconsistent drug availability and } \\
\text { affordability } \\
\text { Lack of education and strategies for } \\
\text { increasing acceptance and adherence to } \\
\text { long-term therapy } \\
\text { Insufficient epidemiological data on NCDs } \\
\text { and risk factors } \\
\text { Reduced operational research and low } \\
\text { scientific output }\end{array}$ & $\begin{array}{l}\text { Invest in equitable and high-quality primary care to better detect and manage risk factors such as high blood } \\
\text { pressure, alcohol abuse, and diabetes mellitus } \\
\text { Implement continuous training of clinicians and nonphysician health providers on prevention and management } \\
\text { of CVDs } \\
\text { Develop context-specific guidelines and algorithms for risk stratification and medical management of high-risk } \\
\text { individuals at the primary level } \\
\text { Make lower-cost tests available in low-income settings } \\
\text { Increase access to essential medicines for CVD by defining the minimum package for the primary healthcare } \\
\text { level and promoting simplified regimens, generic drugs, and combination tablets } \\
\text { Promote systems for cost recovery tailored to the setting and the mode of living of local communities } \\
\text { Strengthen the routine health information system, imposing compulsory notification of CVD }\end{array}$ \\
\hline $\begin{array}{l}\text { Lack of comprehensive agenda for CVD } \\
\text { prevention and control } \\
\text { Lack of regulatory tools for risk factor } \\
\text { control } \\
\text { Health policy decision makers' inertia to } \\
\text { legislate toward access to healthy diet and } \\
\text { good lifestyle } \\
\text { Lack of population-level strategies for blood } \\
\text { pressure control } \\
\text { Unhealthy patient behavior and knowledge } \\
\text { of prevention of NCD }\end{array}$ & $\begin{array}{l}\text { Incorporate strategies for health education and integrate risk factor control and initial management of CVD into } \\
\text { primary health care } \\
\text { Regulate toward reduction of caloric intake, use of polyunsaturated fats, and reduction of alcohol consumption } \\
\text { Apply the FCTC provisions aimed at reducing the supply of and demand for tobacco products (eg, ban public } \\
\text { smoking and increase price of tobacco) } \\
\text { Establish limits on salt for the more commonly used packaged foods and staples such as flour and bread } \\
\text { Promote healthy food choices by taxing unhealthy food choices and improving access to fresh fruits and } \\
\text { vegetables } \\
\text { Educate the public and health professionals about regular physical activity in urban populations and introduce } \\
\text { screening for high blood pressure at community level } \\
\text { Impose better planning of cities, creating common open spaces for exercise and active leisure } \\
\text { Promote financial risk protection and universal health coverage }\end{array}$ \\
\hline $\begin{array}{l}\text { Inadequate infrastructure for research and } \\
\text { innovation } \\
\text { Small pool of scientists } \\
\text { Low investment in R\&D infrastructure } \\
\text { Lack of S\&T culture } \\
\text { Lack of recognition of the scientist's role }\end{array}$ & $\begin{array}{l}\text { Improve S\&T infrastructure as part of poverty alleviation strategies } \\
\text { Implement Africa's S\&T Consolidated Plan of Action } \\
\text { Progressively increase the percent of GDP allocated to R\&D } \\
\text { Reduce reliance on external financial support, which often targets short-term goals } \\
\text { Invest in regulation that promotes public-private partnerships on research } \\
\text { Provide incentives to students for engineering and new technologies }\end{array}$ \\
\hline
\end{tabular}

CVD indicates cardiovascular disease; FCTC, Framework Convention for Tobacco Control; GDP, gross domestic product; NCD, noncommunicable disease; R\&D, research and development; S\&T, science and technology; and WHO, World Health Organization.

leadership has moved from skepticism to investment in portable and battery-powered laboratory devices, training of nonspecialists on the use of diagnostic tools and provision of care, and promotion of the use of multiplex rapid test systems at point of care for the assessment of cardiovascular risk factors.

Finally, partnerships with the other players in the government are essential, for example, interventions and legislation for the promotion of healthy food, healthy working environment and physical activity at workplace.

\section{Conclusions}

We have provided evidence that Africa is a continent characterized by marked ethnic, sociodemographic, and economic diversity. Profound changes have occurred in many regions over the past 2 decades that have had an impact on CVD presentation and outcomes. Within Africa and the individual countries, one can find regions affected predominantly by communicable diseases. Concomitantly, there is an increase in the number of areas affected by a marked increase in obesity, diabetes mellitus, smoking, and cholesterol. These factors lead to a double burden of communicable and noncommunicable disease on the continent.

Poor data and low investment in R\&D in almost all African countries have resulted in very limited data on CVDs and risk factors for most countries, which complicates effective healthcare planning. Therefore, strengthening of health system and investment in surveys to describe the pattern of noncommunicable diseases in the continent are mandatory. Collaborative programs involving the communities, the industry, and partnerships from other sectors of the government would likely lead to better overall use of resources and result in national and continental growth.

\section{Acknowledgments}

We acknowledge the support of Sylvia Dennis, Hatter Institute for Cardiovascular Research in Africa, in preparing this manuscript. 


\section{Sources of Funding}

This research could not have been conducted without the funding support of the University of Cape Town, Medical Research Council South Africa, National Research Foundation South Africa, Maurice Hatter Foundation, and Servier.

\section{Disclosures}

None.

\section{References}

1. Yusuf S, Reddy S, Ounpuu S, Anand S. Global burden of cardiovascular diseases, part II: variations in cardiovascular disease by specific ethnic groups and geographic regions and prevention strategies. Circulation. 2001;104:2855-2864.

2. Vorster HH. The emergence of cardiovascular disease during urbanisation of Africans. Public Health Nutr. 2002;5:239-243.

3. Mensah GA. Descriptive epidemiology of cardiovascular risk factors and diabetes in sub-Saharan Africa. Prog Cardiovasc Dis. 2013;56:240-250. doi: 10.1016/j.pcad.2013.10.014.

4. Danaei G, Singh GM, Paciorek CJ, Lin JK, Cowan MJ, Finucane MM, Farzadfar F, Stevens GA, Riley LM, Lu Y, Rao M, Ezzati M, Global Burden of Metabolic Risk Factors of Chronic Diseases Collaborating Group. The global cardiovascular risk transition: associations of four metabolic risk factors with national income, urbanization, and Western diet in 1980 and 2008. Circulation. 2013;127:1493-1502, 1502e1491-1498.

5. Mocumbi AO, Sliwa K. Women's cardiovascular health in Africa. Heart. 2012;98:450-455. doi: 10.1136/heartjnl-2011-301025.

6. Thienemann F, Sliwa K, Rockstroh JK. HIV and the heart: the impact of antiretroviral therapy: a global perspective. Eur Heart J. 2013;34:35383546. doi: 10.1093/eurheartj/eht388.

7. Sliwa K, Carrington MJ, Becker A, Thienemann F, Ntsekhe M, Stewart S. Contribution of the human immunodeficiency virus/acquired immunodeficiency syndrome epidemic to de novo presentations of heart disease in the Heart of Soweto Study cohort. Eur Heart J. 2012;33:866-874. doi: 10.1093/eurheartj/ehr398.

8. Jerven M. Poor Numbers: How We Are Misled by African Developmental Statistics and What to Do About It. New York: Cornell University Press; 2013.

9. Jerven M. Poor numbers and what to do about them. Lancet. 2014;383:594-595.

10. Heine B, Nurse D. African Languages: An Introduction. London, UK: Cambridge University Press; 2000.

11. Kim D, Kawachi I, Hoorn SV, Ezzati M. Is inequality at the heart of it? Cross-country associations of income inequality with cardiovascular diseases and risk factors. Soc Sci Med. 2008;66:1719-1732. doi: 10.1016/j. socscimed.2007.12.030.

12. Mayosi BM, Lawn JE, van Niekerk A, Bradshaw D, Abdool Karim SS, Coovadia HM; Lancet South Africa Team. Health in South Africa: changes and challenges since 2009. Lancet. 2012;380:2029-2043. doi: 10.1016/S0140-6736(12)61814-5.

13. Sliwa K, Damasceno A, Mayosi BM. Epidemiology and etiology of cardiomyopathy in Africa. Circulation. 2005;112:3577-3583. doi: 10.1161/ CIRCULATIONAHA.105.542894.

14. Steyn K, Sliwa K, Hawken S, Commerford P, Onen C, Damasceno A, Ounpuu S, Yusuf S; INTERHEART Investigators in Africa. Risk factors associated with myocardial infarction in Africa: the INTERHEART Africa study. Circulation. 2005;112:3554-3561. doi: 10.1161/ CIRCULATIONAHA.105.563452.

15. Finucane MM, Stevens GA, Cowan MJ, Danaei G, Lin JK, Paciorek CJ, Singh GM, Gutierrez HR, Lu Y, Bahalim AN, Farzadfar F, Riley LM, Ezzati M; Global Burden of Metabolic Risk Factors of Chronic Diseases Collaborating Group (Body Mass Index). National, regional, and global trends in body-mass index since 1980: systematic analysis of health examination surveys and epidemiological studies with 960 country-years and $9 \cdot 1$ million participants. Lancet. 2011;377:557-567. doi: 10.1016/ S0140-6736(10)62037-5.

16. Farzadfar F, Finucane MM, Danaei G, Pelizzari PM, Cowan MJ, Paciorek CJ, Singh GM, Lin JK, Stevens GA, Riley LM, Ezzati M; Global Burden of Metabolic Risk Factors of Chronic Diseases Collaborating Group (Cholesterol). National, regional, and global trends in serum total cholesterol since 1980: systematic analysis of health examination surveys and epidemiological studies with 321 country-years and
3.0 million participants. Lancet. 2011;377:578-586. doi: 10.1016/ S0140-6736(10)62038-7.

17. Danaei G, Finucane MM, Lu Y, Singh GM, Cowan MJ, Paciorek CJ, Lin JK, Farzadfar F, Khang YH, Stevens GA, Rao M, Ali MK, Riley LM, Robinson CA, Ezzati M; Global Burden of Metabolic Risk Factors of Chronic Diseases Collaborating Group (Blood Glucose). National, regional, and global trends in fasting plasma glucose and diabetes prevalence since 1980: systematic analysis of health examination surveys and epidemiological studies with 370 country-years and 2.7 million participants. Lancet. 2011;378:31-40. doi: 10.1016/S0140-6736(11)60679-X.

18. Danaei G, Finucane MM, Lin JK, Singh GM, Paciorek CJ, Cowan MJ, Farzadfar F, Stevens GA, Lim SS, Riley LM, Ezzati M; Global Burden of Metabolic Risk Factors of Chronic Diseases Collaborating Group (Blood Pressure). National, regional, and global trends in systolic blood pressure since 1980: systematic analysis of health examination surveys and epidemiological studies with 786 country-years and 5.4 million participants. Lancet. 2011;377:568-577. doi: 10.1016/ S0140-6736(10)62036-3.

19. International Diabetes Federation, IDF Diabetes Atlas. 6th ed, Brussels, Belgium: International Diabetes Federation; 2013. http://www.idf.org

20. Non-Communicable Disease Country-Specific Profiles 2011: WHO Global Report. Geneva, Switzerland: World Health Organization; 2011.

21. World Health Organization. WHO Global Comparable Estimates. 2005. https://apps.who.int.infobase/Comparisons.aspx. Accessed February 3, 2016.

22. World Health Organization. WHO Report on the Global Tobacco Epidemic 2009: Implementing Smoke-Free Environments. Geneva, Switzerland: World Health Organization; 2009. http://www.who.int/ tobacco/mpower/2009/en/. Accessed February 3, 2016.

23. Ezzati M, Vander Hoorn S, Lawes CM, Leach R, James WP, Lopez AD, Rodgers A, Murray CJ. Rethinking the "diseases of affluence" paradigm: global patterns of nutritional risks in relation to economic development. PLoS Med. 2005;2:e133. doi: 10.1371/journal.pmed.0020133.

24. Pampel FC, Denney JT, Krueger PM. Obesity, SES, and economic development: a test of the reversal hypothesis. Soc Sci Med. 2012;74:10731081. doi: 10.1016/j.socscimed.2011.12.028.

25. Goyal A, Bhatt DL, Steg PG, Gersh BJ, Alberts MJ, Ohman EM, Corbalán R, Eagle KA, Gaxiola E, Gao R, Goto S, D'Agostino RB, Califf RM, Smith SC Jr, Wilson PW; Reduction of Atherothrombosis for Continued Health (REACH) Registry Investigators. Attained educational level and incident atherothrombotic events in low- and middle-income compared with high-income countries. Circulation. 2010;122:1167-1175. doi: 10.1161/CIRCULATIONAHA.109.919274.

26. Tumwine J. Implementation of the framework convention on tobacco control in Africa: current status of legislation. Int J Environ Res Public Health. 2011;8:4312-4331. doi: 10.3390/ijerph8114312.

27. Pampel F. Tobacco use in sub-Sahara Africa: estimates from the demographic health surveys. Soc Sci Med. 2008;66:1772-1783. doi: 10.1016/j. socscimed.2007.12.003.

28. Press WH. Presidential address: what's so special about science (and how much should we spend on it?). Science. 2013;342:817-822.

29. Arrow K. Economic Welfare and the Allocation of Resources for Invention. In: The Rate and Direction of Inventive Activity: Economic and Social Factors. Universities-National Bureau Committee for Economic Research (eds). Princeton Universiy Press. 1962, p609-626.

30. The Current State of Science Around the World. Paris, France: United Nations Educational, Scientific and Cultural Organization; 2010. UNESCO Science Report 2010.

31. Sliwa K, Mocumbi AO. Forgotten cardiovascular diseases in Africa. Clin Res Cardiol. 2010;99:65-74. doi: 10.1007/s00392-009-0094-1.

32. Nel G, Mayosi B, Sliwa K. CardioPulse: Pan-African Society of Cardiology: an overview of the society's important activities in 2014. Eur Heart J. 2014;35:2700-2702.

33. Ottersen OP, Dasgupta J, Blouin C, Buss P, Chongsuvivatwong V, Frenk J, Fukuda-Parr S, Gawanas BP, Giacaman R, Gyapong J, Leaning J, Marmot M, McNeill D, Mongella GI, Moyo N, Møgedal S, Ntsaluba A, Ooms G, Bjertness E, Lie AL, Moon S, Roalkvam S, Sandberg KI, Scheel IB. The political origins of health inequity: prospects for change. Lancet. 2014;383:630-667. doi: 10.1016/S0140-6736(13)62407-1.

34. Gostin LO. Why rich countries should care about the world's least healthy people. JAMA. 2007;298:89-92. doi: 10.1001/jama.298.1.89.

35. Stringhini S, Sinon F, Didon J, Gedeon J, Paccaud F, Bovet P. Declining stroke and myocardial infarction mortality between 1989 and 2010 in a country of the African region. Stroke. 2012;43:2283-2288. doi: 10.1161/ STROKEAHA.112.658468. 
36. Mathers CD, Fat DM, Inoue M, Rao C, Lopez AD. Counting the dead and what they died from: an assessment of the global status of cause of death data. Bull World Health Organ. 2005;83:171-177. doi: / S0042-96862005000300009.

37. Gersh BJ, Sliwa K, Mayosi BM, Yusuf S. Novel therapeutic concepts: the epidemic of cardiovascular disease in the developing world: global implications. Eur Heart J. 2010;31:642-648. doi: 10.1093/eurheartj/ehq030.

38. Kwan GF, Bukhman AK, Miller AC, Ngoga G, Mucumbitsi J, Bavuma C, Dusabeyezu S, Rich ML, Mutabazi F, Mutumbira C, Ngiruwera JP, Amoroso C, Ball E, Fraser HS, Hirschhorn LR, Farmer P, Rusingiza E, Bukhman G. A simplified echocardiographic strategy for heart failure diagnosis and management within an integrated noncommunicable disease clinic at district hospital level for sub-Saharan Africa. JACC Heart Fail. 2013;1:230-236. doi: 10.1016/j.jchf.2013.03.006.

39. Brentlinger PE, Assan A, Mudender F, Ghee AE, Vallejo Torres J, Martínez Martínez P, Bacon O, Bastos R, Manuel R, Ramirez Li L, McKinney C, Nelson LJ. Task shifting in Mozambique: cross-sectional evaluation of non-physician clinicians' performance in HIV/AIDS care. Hum Resour Health. 2010;8:23. doi: 10.1186/1478-4491-8-23.

40. Feldacker C, Chicumbe S, Dgedge M, Augusto G, Cesar F, Robertson M, Mbofana F, O’Malley G. Mid-level healthcare personnel training: an evaluation of the revised, nationally-standardized, pre-service curriculum for clinical officers in Mozambique. PLoS One. 2014;9:e102588. doi: 10.1371/journal.pone.0102588. 


\title{
Circulation
}

\section{Impact of Socioeconomic Status, Ethnicity, and Urbanization on Risk Factor Profiles of Cardiovascular Disease in Africa \\ Karen Sliwa, Letitia Acquah, Bernard J. Gersh and Ana Olga Mocumbi}

Circulation. 2016;133:1199-1208

doi: 10.1161/CIRCULATIONAHA.114.008730

Circulation is published by the American Heart Association, 7272 Greenville Avenue, Dallas, TX 75231

Copyright (C) 2016 American Heart Association, Inc. All rights reserved.

Print ISSN: 0009-7322. Online ISSN: 1524-4539

The online version of this article, along with updated information and services, is located on the World Wide Web at:

http://circ.ahajournals.org/content/133/12/1199

\begin{abstract}
Permissions: Requests for permissions to reproduce figures, tables, or portions of articles originally published in Circulation can be obtained via RightsLink, a service of the Copyright Clearance Center, not the Editorial Office. Once the online version of the published article for which permission is being requested is located, click Request Permissions in the middle column of the Web page under Services. Further information about this process is available in the Permissions and Rights Question and Answer document.
\end{abstract}

Reprints: Information about reprints can be found online at: http://www.lww.com/reprints

Subscriptions: Information about subscribing to Circulation is online at: http://circ.ahajournals.org//subscriptions/ 